\title{
Non drowsy obstructive sleep apnea as a potential cause of resistant hypertension: a case report
}

\author{
Aibek E Mirrakhimov ${ }^{1,2^{*}}$
}

\begin{abstract}
Background: Obstructive sleep apnea (OSA) and arterial hypertension (AH) are common and underrecognized medical disorders. OSA is a potential risk factor for the development of AH and/or may act as a factor complicating AH management. The symptoms of excessive daytime sleepiness (EDS) are considered essential for the initiation of continuous positive airway pressure (CPAP) therapy, which is a first line treatment of OSA. The medical literature and practice is controversial about the treatment of people with asymptomatic OSA. Thus, OSA patients without EDS may be left at increased cardiovascular risk.

Case presentation: The report presents a case of 42 year old Asian woman with symptoms of heart failure and angina like chest pain upon admission. She didn't experience symptoms of EDS, and the Epworth Sleepiness Scale was seven points. Snoring was reported on direct questioning. The patient had prior medical history of three unsuccessful pregnancies complicated by gestational AH and preeclampsia with C-section during the last pregnancy. The admission blood pressure (BP) was 200/120 mm Hg. The patient's treatment regimen consisted of five hypotensive medications including diuretic. However, a target BP wasn't achieved in about one and half month. The patient was offered to undergo a polysomnography (PSG) study, which she rejected. One month after discharge the PSG study was done, and this showed an apnea-hypopnea index (AHI) of 46 events per hour. CPAP therapy was initiated with a pressure of $11 \mathrm{H}_{2} \mathrm{O} \mathrm{cm}$. After 2 months of compliant CPAP use, adherence to pharmacologic regimen and lifestyle modifications the patient's BP decreased to 134/82 mm Hg.

Conclusions: OSA and AH are common and often underdiagnosed medical disorders independently imposing excessive cardiovascular risk on a diseased subject. When two conditions coexist the cardiovascular risk is likely much greater. This case highlights a possible clinical phenotype of OSA without EDS and its association with resistant $\mathrm{AH}$. Most importantly a good hypotensive response to medical treatment in tandem with CPAP therapy was achieved in this patient. Thus, it is reasonable to include OSA in the differential list of resistant AH, even if EDS is not clinically obvious.
\end{abstract}

Keywords: Sleep Apnea, Arterial Hypertension, Resistant Hypertension, Obesity

\footnotetext{
Correspondence: amirrakhimov1@gmail.com

${ }^{1}$ Kyrgyz State Medical Academy named after I.K. Akhunbaev, Akhunbaev street 92, Bishkek 720020, Kyrgyzstan

${ }^{2}$ National Centre of Cardiology and Internal Medicine named after $\mathrm{M}$. Mirrakhimov, T.Moldo 3, Bishkek 720040, Kyrgyzstan
}

\section{Ciomed Central}

(C) 2012 Mirrakhimov; licensee BioMed Central Ltd. This is an Open Access article distributed under the terms of the Creative Commons Attribution License (http://creativecommons.org/licenses/by/2.0), which permits unrestricted use, distribution, and reproduction in any medium, provided the original work is properly cited. 


\section{Background}

Obstructive sleep apnea (OSA)-is the disorder characterized by complete or partial breathing disturbances during sleep with a minimum prerequisite frequency of 5 events per hour and lasting for at least 10 seconds [1]. The prevalence of OSA varies in epidemiological surveys, and this can be explained by different populations studied and including excessive daytime sleepiness (EDS) as a criterion for OSA diagnosis [2]. Thus, it is likely that the real number of the affected population is much higher than reported.

OSA is associated with increased cardiovascular risk and OSA in particular may be an independent risk factor for the development of arterial hypertension (AH) [3]. $\mathrm{AH}$ on the other hand, is a major cardiovascular risk factor and among the most prevalent chronic conditions worldwide [4]. The association between $\mathrm{AH}$ and OSA without symptoms of EDS is conflicting and there are controversies regarding the place of continuous positive airway pressure (CPAP) therapy in such situations. Thus, non-sleepy OSA individuals may be dishonestly left with increased cardiovascular risk.

\section{Case presentation}

A 42 year old female of Asian descent was admitted to the ward with complaints of dyspnea and squeezing chest pain without radiation during mild to moderate physical activity, pitting edema of the lower extremities, nocturia and treatment resistant $\mathrm{AH}$. For the last 6 months, the patient experienced shortness of breath and lower extremities pitting edema which had worsened with time. During this period, the patient reported fatigue, which was related to the aforementioned symptoms from the patient's own words. Upon questioning the patient reported loud snoring during sleep, but denied sleepiness during the wake time.

The patient is Gravida 3 Para 0 . The first 2 pregnancies were complicated with gestational hypertension (which were resolved after pregnancies) with stillbirths and the last one with preeclampsia and emergent $\mathrm{C}$-section delivery of demised infant at 30 weeks term.

$\mathrm{AH}$ was diagnosed at 2006, during regular outpatient visit with measured blood pressure (BP) $186 / 110 \mathrm{~mm} \mathrm{Hg}$ at that time. Since then, the patient noticed angina like chest pain during regular physical activity. Family history is remarkable for obesity and $\mathrm{AH}$ in both of her parents.

The patient's prehospitalization regimen consisted of $100 \mathrm{mg}$ of atenolol a day and $20 \mathrm{mg}$ of enalapril a day, which is not believed to be an optimal hypotensive combination therapy [5]. The patient's BP ranged from 160/ $100 \mathrm{~mm} \mathrm{Hg}$ to $240 / 130 \mathrm{~mm} \mathrm{Hg}$ (which is the highest retrospectively recorded $\mathrm{BP}$ in this patient). The patient denied smoking, alcohol intake or use of any psychostimulating (including caffeine containing products) remedies.
The patient is obese for the last 15 years, but since 2009 she gained approximately 10 kilograms. The patient ate fatty meals with average daily calorie intake of approximately $3000 \mathrm{Kcal} /$ day and followed sedentary lifestyle. The body weight was $103 \mathrm{~kg}$, height was $156 \mathrm{~cm}$, abdominal circumference was $134 \mathrm{~cm}$ and body mass index was $42.3 \mathrm{~kg} / \mathrm{m}^{2}$ upon admission.

Cardiovascular examination: heart rate (HR) was 85 beats per minute. The loud second heart sound was heard over the right second intercostal space. No murmurs, rubs or gallops upon auscultation were heard. Bilateral pitting edema was present over the shins. Admission BP was 200/ $120 \mathrm{~mm} \mathrm{Hg}$.

On the pulmonary exam, bilateral inspiratory rales were present at the bases with no change on coughing. The respiratory rate was 19 per minute. Digital pulse oximetry revealed oxygen saturation of $95 \%$.

Oral examination revealed redundant pharyngeal soft tissue and Mallampati class 3 [6]. Neck circumference was $43 \mathrm{~cm}$ the thyroid gland wasn't palpable. No hair loss, skin changes or alterations in bowel habits were present. Neurological exam was intact. The Epworth sleepiness score (ESS) was seven points [7].

Complete blood count, Creatinine, electrolytes, glomerular filtration rate, liver function tests (ALT, AST), troponin level, fasting lipid panel, fasting glucose (on 2 separate occasions) and thyroid function tests were all within normal limits.

Electrocardiography (ECG): inverted $\mathrm{T}$ waves in leads V3-V6. Holter ECG monitoring: 1 paroxysm of atrial fibrillation with $\mathrm{HR}$ of 134 beats/minute lasting for 21 seconds. Frequent episodes of $\mathrm{T}$ wave inversion without overt ST segment abnormalities.

Echocardiography: left ventricular end diastolic dimension: $6.45 \mathrm{~cm}$, left ventricular end systolic dimension: $5.01 \mathrm{~cm}$, interventricular septum: $1.36 \mathrm{~cm}$, posterior wall of the left ventricle: $1.27 \mathrm{~cm}$ and ejection fraction of $43 \%$. Mild diffuse left ventricular hypokinesis was present. Other parameters were within normal limits.

Carotid ultrasound: left common carotid intima media thickness of 0.91 and right common carotid TIM of 0.92 without obvious plaques.

24 hour BP measurement: non dipping pattern, with only $3 \%$ of nighttime decline of BP. Important to note that nighttime $\mathrm{BP}$ is known to be a stronger predictor of cardiovascular events than daytime BP [8].

Chest X-Ray: Pulmonary venous congestion and cardiothoracic index of $49 \%$.

The hospital stay was 20 days. The patient's hypotensive regimen is present in Table 1 . On this regimen the patient's $\mathrm{BP}$ ranged from 150/90 to170/110 $\mathrm{mm} \mathrm{Hg}$. HR was 62-70 beats per minute. Besides the pharmacological intervention, the patient was counseled on proper low fat/calorie diet and other measures to improve her lifestyle. 
Table 1 Hypotensive regimen at the hospital

\begin{tabular}{ll}
\hline Medication & Dose \\
\hline Bisoprolol & $10 \mathrm{mg}$ a day \\
\hline Candesartan & $32 \mathrm{mg}$ a day \\
\hline Indapamide SR & $1.5 \mathrm{mg}$ a day \\
\hline Amlodipine & $10 \mathrm{mg}$ a day \\
\hline Moxonidine & $400 \mathrm{mcg}$ a day \\
\hline
\end{tabular}

The patient was considered to have resistant AH. Since this patient was obese and had high diastolic BP some possible alternative etiologies were considered such as obesity related $\mathrm{AH}$, hypothyroidism, OSA etc.

Since OSA was in the differential list, this patient was offered a PSG study, which she rejected at that time.

The patient was discharged with the BP of $160 / 106 \mathrm{~mm}$ $\mathrm{Hg}$ and instructed to return for follow up visit in 2 weeks as outpatient.

The patient arrived only 1 month after and assured that she didn't have any compliance related problems. The BP was 158/110 mm Hg. Dyspnea became less severe and the angina episodes less frequent.

The possibility of OSA was again discussed with the patient and PSG study was offered, which was agreed at that time. The recording of the patient's PSG study is present in Figure 1.

The 12 hour PSG revealed the apnea-hypopnea index (AHI) of 46 events per hour, which is consistent with a severe form of the disease [1]. On the next night, the CPAP titration study with the pressure of $11 \mathrm{H}_{2} \mathrm{O} \mathrm{cm}$ abolished the sleep disordered breathing events. The patient was instructed on proper and compliant use of CPAP machine. Follow up was scheduled in 2 months.

After 2 months, the patient's CPAP using time was on average 6 hours per night and 7 days a week. The BP on this visit was $140 / 92 \mathrm{~mm} \mathrm{Hg}$ on prior pharmacological regimen and CPAP therapy.

One month later, the patient's BP became 134/82 mm Hg. The patient's treatment regimen wasn't modified during this time interval. Home sleep monitoring detected the AHI of six events per hour.

\section{Discussion}

Resistant $\mathrm{AH}$ is defined as inability to reach target $\mathrm{BP}$ using at least 3 different hypotensive medications including diuretic [9]. The differential list is broad and includes: lack of treatment compliance, inadequate treatment regimen, hypervolemic states, identifiable causes of $\mathrm{AH}$, obesity and OSA [10].

It is well known that OSA is a potential risk factor for $\mathrm{AH}$ development and/or a factor complicating its treatment. Currently the symptoms of EDS are considered essential for the initiation of CPAP therapy, while patients with pathologic AHI and without EDS are generally not treated. However, it is noteworthy to mention that OSA with EDS has the strongest association with resistant AH [11].

In their landmark study, Barbe and colleagues highlighted the beneficial effects of CPAP therapy in nonsleepy OSA subjects who were compliant with CPAP therapy. However in their study the effect on BP was only evident after one year of regular CPAP therapy [12].

In this patient several issues should be considered. First, this is only a case report with all potential limitations. Second, the impact of obesity and insulin resistance weren't measured in the patient, but it is important to mention that the patient didn't lose weight within the 3 months follow up. Third, the patient decreased her sodium intake from eight grams to four grams a day and

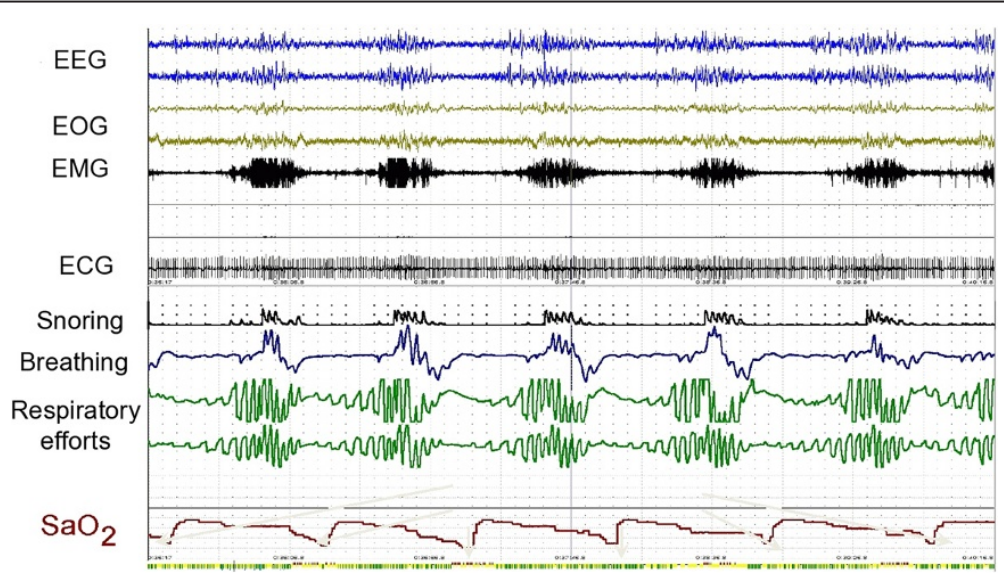

Figure 1 Patient's PSG recording. Abbreviations: ECG-electrocardiography, EEG-electroencephalography, EMG-electromyography, EOG-electrooculography, SaO2-oxygen saturation. 
started mild to moderate aerobic physical exercises. Fourth, the BP decline may be solely explained by hypotensive effect of BP lowering medications. Fifth, ESS is known to have some limitations, since it is a subjective test for EDS [13]. A recent study highlighted the fact that patients with OSA and concomitant heart failure (HF) can present without symptoms of EDS assessed with ESS [14]. However, others in a smaller number of recruited participants have failed to show that patients with OSA and HF have less EDS [15]. But, on the other hand, ESS may have limited sensitivity for detecting EDS in patients with OSA and concomitant HF.

Nevertheless, this report highlights the possibility of a distinct non sleepy clinical phenotype of OSA and its association with resistant $\mathrm{AH}$. Thus, it is reasonable to include OSA in the differential list of refractory to treatment $\mathrm{AH}$, even when the EDS is not clinically obvious.

\section{Conclusion}

OSA and $\mathrm{AH}$ are common and often underdiagnosed medical disorders independently imposing excessive cardiovascular risk on diseased subject. When two conditions coexist the burden is likely much greater. This case highlights a possible association between non-sleepy OSA and $\mathrm{AH}$, with good hypotensive response to $\mathrm{BP}$ lowering medications in tandem with CPAP therapy. Thus, it is reasonable to include OSA in the differential list of refractory to treatment $\mathrm{AH}$, even when the EDS is not clinically obvious.

\section{Consent}

Written informed consent was obtained from the patient for publication of this Case report and any accompanying images. A copy of the written consent is available for review by the Series Editor of this journal.

\section{Abbreviations \\ $\mathrm{AH}$ : Arterial hypertension; AHI: Apnea hypopnea index; BP: Blood pressure; CPAP: Continuous positive airway pressure; ECG: electrocardiography; EDS: Excessive daytime sleepiness; ESS: Epworth sleepiness score; HF: Heart failure; HR: Heart rate; OSA: Obstructive sleep apnea; PSG: Polysomnography.}

\section{Competing of interest}

The author declare that he has no competing interests.

Received: 22 December 2011 Accepted: 25 April 2012

Published: 25 April 2012

\section{References}

1. Sleep-related breathing disorders in adults: recommendations for syndrome definition and measurement techniques in clinical research. The report of an American Academy of Sleep Medicine Task force. Sleep 1999, 22:667-689

2. Young T, Palta M, Dempsey J, Skatrud J, Weber S, Badr S: The occurrence of sleep disordered breathing among middle aged adults. $N$ Engl I Med 1993, 328:1230-1235.

3. Gonçalves SC, Martinez D, Gus M, de Abreu-Silva EO, Bertoluci C, Dutra I, Branchi T, Moreira LB, Fuchs SC, de Oliveira AC, Fuchs FD: Obstructive sleep apnea and resistant hypertension: a case-control study. Chest 2007, 132:1858-1862.
4. Kearney PM, Whelton M, Reynolds K, Muntner P, Whelton PK, He J: Global burden of hypertension: analysis of worldwide data. Lancet 2005, 365:217-223.

5. 2007 Guidelines for the management of arterial hypertension: The Task Force for the Management of Arterial Hypertension of the European Society of Hypertension (ESH) and of the European Society of Cardiology (ESC). Eur Heart J 2007, 28:1462-1536.

6. Hiremath AS, Hillman DR, James AL, Noffsinger WJ, Platt PR, Singer SL: Relationship between difficult tracheal intubation and obstructive sleep apnoea. Br J Anaesth 1998, 80:606-611.

7. Johns MW: A new method for measuring daytime sleepiness: the Epworth sleepiness scale. Sleep 1991, 14:540-545.

8. Dolan E, Stanton A, Thiis L, Hinedi K, Atkins N, McClory S, Den Hond E, McCormack P, Staessen JA, O'Brien E: Superiority of ambulatory over clinic blood pressure measurement in predicting mortality: the Dublin outcome study. Hypertension 2005, 46:156-161.

9. The Seventh Report of the Joint National Committee on Prevention Detection, Evaluation, and Treatment of High Blood Pressure: the JNC 7 report. JAMA 2003, 289:2560-2572.

10. Pisoni R, Ahmed Ml, Calhoun DA: Characterization and treatment of resistant hypertension. Curr Cardiol Rep 2009, 11:407-413.

11. Calhoun DA: Obstructive sleep apnea and hypertension. Curr Hypertens Rep 2010, 12:189-195.

12. Barbé F, Durán-Cantolla J, Capote F, de la Peña M, Chiner E, Masa JF, Gonzalez M, Marín JM, Garcia-Rio F, de Atauri JD, Terán J, Mayos M, Monasterio C, del Campo F, Gomez S, de la Torre MS, Martinez M, Montserrat JM: Long-term effect of continuous positive airway pressure in hypertensive patients with sleep apnea. Am J Respir Crit Care Med 2010 181:718-726.

13. Short M, Lack L, Wright H: Does subjective sleepiness predict objective sleep propensity? Sleep 2010, 33:123-129.

14. Ferreira S, Marinho A, Patacho M, Santa-Clara E, Carrondo C, Winck J, Bettencourt P: Prevalence and characteristics of sleep apnoea in patients with stable heart failure: Results from a heart failure clinic. BMC Pulm Med 2010, 10:9.

15. Patidar $A B$, Andrews GR, Seth S: Prevalence of obstructive sleep apnea, associated risk factors, and quality of life among Indian congestive heart failure patients: a cross-sectional survey. J Cardiovasc Nurs 2011, 26:452-459.

doi:10.1186/1471-2466-12-16

Cite this article as: Mirrakhimov: Non drowsy obstructive sleep apnea as a potential cause of resistant hypertension: a case report. BMC Pulmonary Medicine 2012 12:16

\section{Submit your next manuscript to BioMed Central and take full advantage of:}

- Convenient online submission

- Thorough peer review

- No space constraints or color figure charges

- Immediate publication on acceptance

- Inclusion in PubMed, CAS, Scopus and Google Scholar

- Research which is freely available for redistribution 